\title{
Effect of polydextrose-containing beverage on bowel habits and gastrointestinal symptoms of constipated subjects: a pilot study
}

\section{Mohamad Yulianto Kurniawan, Nourmatania Istiftiani*, Lilis Heryati, Christian Reinaldo \& Fendy Susanto}

${ }^{1}$ Department of Scientific and Regulatory Affairs, PT. Amerta Indah Otsuka, Jakarta, Indonesia

\begin{abstract}
Introduction: Indonesians have a low intake of dietary fibre, a key component for an increased incidence in constipation. Available data have documented the benefits of polydextrose (PDX) in healthy subjects. However, data on constipated subjects are lacking. This study aimed to investigate the effect of consuming a PDX (prebiotic) beverage on bowel habits and gastrointestinal symptoms of constipated subjects over seven days. Methods: This was a randomised, non-blinded, nonplacebo-controlled parallel design study involving 24 subjects, divided equally into two groups. Group A (active control group) consisted of 12 subjects, consuming one serving size of $6 \mathrm{~g}$ PDX beverage. While Group B (intervention group) consisted of 12 subjects, consuming two servings of the same product, containing $12 \mathrm{~g}$ PDX beverage. Changes in bowel habits (constipation score, stool frequency and stool consistency) and gastrointestinal symptoms (abdominal pain, bloating and flatulence) were monitored. Results: Within seven days, Group B showed 4.9\% more reduction in overall constipation mean score than that of Group A. Positive improvement in gastrointestinal symptoms were reported: i.e. abdominal pain $(\Delta M=-0.08 \pm 0.43)$, bloating $(\Delta M=-0.29 \pm 0.37)$ and flatulence $(\Delta M=-0.17 \pm 0.47)$. Majority of subjects had desirable stool frequency $(87.5 \%,>3$ defecations/week) and stool consistency (58.3\%, type 4). These improvements were due to the fact that PDX provides physiological effects consistent with prebiotic fibre, which alters the gut microbiota composition during the fermentation cycle in the large intestine. Conclusion: Findings of this study suggested that daily PDX beverage consumption effectively improved bowel habits, with fewer constipated subjects reporting of gastrointestinal symptoms.
\end{abstract}

Keywords: Bowel habits, constipation, dietary fibre, gastrointestinal symptoms, polydextrose

\section{INTRODUCTION}

Gastrointestinal disorders, such as constipation, continue to be one of the public health issues worldwide. The prevalence of this phenomenon can vary depending on geographical regions, ranging from $0.7 \%-29.6 \%$ in children, and from $2.0 \%-35.0 \%$ among adults in Europe, Oceania, and North America (Mugie, Benninga \& Di Lorenzo, 2011). In developing countries like Malaysia and Indonesia, the prevalence of

\footnotetext{
*Corresponding author: Nourmatania Istiftiani, SKM Department of Scientific and Regulatory Affairs, PT Amerta Indah Otsuka, Jakarta, Indonesia Tel: (6221)7697475; Fax: (6221)7697472; E-mail: nistiftiani@aio.co.id doi: https://doi.org/10.31246/mjn-2019-0052
} 
constipation is quite high at $32.3 \%$ and $58.0 \%$, respectively (Wahab et al., 2019; Yudiyanto, 2018). It was reported that constipation afflicted a wide age range, starting at age 60 years (Wahab et al., 2019) or even earlier (12-17 years old) (Yudiyanto, 2018).

Constipation is generally described based on subjective-reported symptoms, which commonly include unsatisfactory condition due to infrequency in defecation $(<3$ times a week), difficulty in passing stool (severity of false alarm), and feeling of incomplete evacuation (Chan et al., 2005). Its pathogenesis is influenced by many factors, amongst them genetic susceptibility, socioeconomic status, dietary type or daily behaviour (Forootan, Bagheri \& Darvishi 2018).

Prior to the introduction of prebiotics in modifying gut microbiota, treatment of constipation in children and adults ranged from toilet training, acupuncture therapy to therapeutic measures like laxative use, polyethylene glycol or bisacodyl (Philichi, 2018; Mounsey, Raleigh \& Wilson, 2015). A recent study indicated that the initial management of constipation should be controlled at primary intervention, especially by adjusting lifestyle and dietary habits (Forootan, Bagheri \& Darvishi, 2018).

There is emerging evidence supporting that dietary habits can alter the composition of gut microbiota, thus leading to changes in defecation frequency and consistency (Lee et al. 2017). For instance, additional fibre intake, both soluble and insoluble, is one of the most effective dietary approaches in reducing constipation (Chey, 2017). Scientific evidences have also demonstrated that polydextrose (PDX), a soluble prebiotic fibre, bulking agent and humectant can potentially improve faecal bulk, soften the stools and increase the number of defecation (Ibarra et al., 2019; Do Carmo et al., 2016). Various studies have documented the positive effect of PDX intake on constipation. A study led by Costabile et al. (2012) conducted on 31 healthy adults concluded that the administration of PDX significantly improved bowel function, reduced abdominal discomfort and softened stool consistency. Another study reported that a 2 -week regular consumption of PDX greatly improved bowel function by decreasing the feeling of incomplete bowel evacuation and judgement of constipation compared to baseline time point (Ibarra et al., 2019).

Nevertheless, majority of data used healthy subjects as subjects under intervention. Data on the benefits of PDX in improving defecation among subjects experiencing constipation are lacking. Therefore, our study was designed with the main objective to investigate the effect of consuming a PDX (prebiotic) beverage on bowel habits and gastrointestinal symptoms in constipated subjects, which builds on the strength of evidence regarding the benefits of prebiotics in improving bowel habits.

\section{MATERIALS AND METHODS}

\section{Study design and population}

A randomised, non-blinded, nonplacebo-controlled trial with a parallel seven-day regular dose-response study on polydextrose (6g vs. $12 \mathrm{~g}$ ) was carried out in January 2019 at PT. Amerta Indah Otsuka and PT. Otsuka Distribution, Indonesia. The study was non-blinded because we aimed to investigate dose responses of PDX in alleviating constipation. Furthermore, we used products available in the market. The study procedure included three phases.

Phase 1 (screening and recruitment phase, day -14)

A total of 323 subjects were recruited from three different sets of PT work place - Amerta Indah Otsuka: Head Office (Jakarta), Pasar Rebo, and Tangerang 
branches. Subjects aged 20-45 years and had experienced constipation in the past two weeks $(n=313)$ were considered for further assessment based on inclusion and exclusion criteria. Also, to minimise selection bias and avoid conflict of interest, detailed explanations were provided to the recruited Otsuka employees, including (i) the participation was voluntary, (ii) no management pressure involved, (iii) non-blinded for subjects and outcome investigator (LH).

Phase 2 (baseline, day 0)

This phase aimed to assess bowel habits, gastrointestinal symptoms, and dietary intake of subjects upon the fulfilment of inclusion and exclusion criteria. The inclusion criteria were subjects with a normal body mass index (BMI) of $18.5-24.9 \mathrm{~kg} / \mathrm{m}^{2}$ (WHO, 2020), did not consume probiotics or prebiotics in the past three months and considered having constipation as diagnosed by the Chinese Constipation Questionnaire (CCQ). Pregnant or lactating women, subjects with a health problem, e.g. diabetes, hypertension, or diarrhoea, or currently using a laxative or other medication likely to affect PDX's mechanism of action and known nature of the product intervention were excluded from the study.

Prior to the study, a brief explanation on the purpose and overall conduct of the study was given, and individual informed consent was signed. The study protocol was approved by the Research Ethics Committee of Atma Jaya Catholic University (No. 1850/III/ LPPM-PM.10.05/12/2018).

A total of 313 subjects willingly participated in the study. The principal investigator (NI) visited all work places for screening of eligibility. A total of 296 out of 313 willing subjects were excluded due to not meeting the inclusion criteria, pregnant or lactating women, had diabetes, hypertension or diarrhoea, and laxative use. Finally, 27 subjects were assigned randomly in a non-blinded manner to consume either one serving size $(100 \mathrm{ml})$ of test beverage product once a day, containing 6g PDX (Group A, $n=14$, considered as active control group), or two servings of the same product, containing $12 \mathrm{~g}$ PDX (Group B, $n=13$, considered as intervention group). Group A consumed the test beverage product at $10 \mathrm{AM}$, whereas Group B consumed at two different times: $10 \mathrm{AM}$ and $3 \mathrm{PM}$. Two levels of PDX concentration were chosen for intervention as these amounts were considered to be tolerated safely for a one-time consumption in humans and can be practically consumed in a real-life setting (per unit bottle). Moreover, the duration of PDX consumption was seven days with consideration of the feasibility and laxative effect of the test beverage product. Furthermore, subjects were instructed to maintain their usual diet during the study, while consuming the test beverage product according to their respected group. During the course of the study, two subjects in Group A and one subject in Group B withdrew from the study due to personal reasons. In total, 24 final subjects completed the study and were included in the statistical analyses. Figure 1 summarises the study flowchart.

Phase 3 (endline, day 7)

At Phase 3, changes in outcome parameters, like bowel habits (constipation score, stool frequency and stool consistency), gastrointestinal symptoms (abdominal pain, bloating and flatulence), and compliance were assessed.

\section{Outcome parameters}

Bowel habits

The selected six-item questionnaire used for constipation diagnosis was adapted from the CCQ (Chan et al., 2005). The 


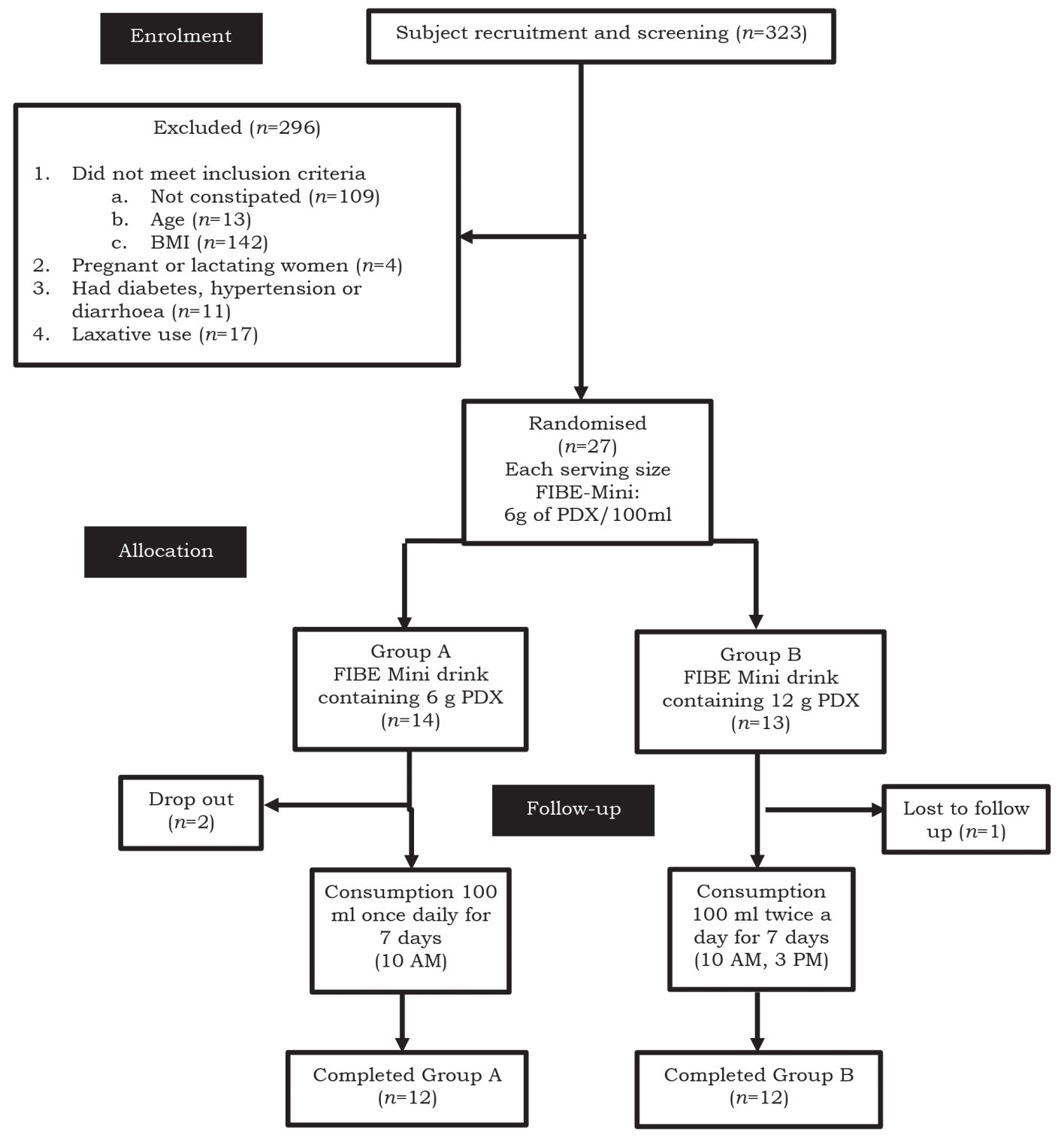

Figure 1. CONSORT flowchart of the study.

following constipation criteria were used: (i) an unsatisfactory condition due to infrequent defecation ( $<3$ times a week), (ii) difficulty passing stool (severity of false alarm), (iii) feeling of incomplete evacuation, (iv) having severe lumpy or hard stools, (v) use of laxative, and (vi) abdominal bloating (Chan et al., 2005).
Constipation scoring was done on a fivepoint Likert scale, i.e. never (0), rarely (1), sometimes (2), often (3), and always (4) (Vagias, 2006). The total score of these six items was added up to determine the final constipation score. Constipation was confirmed when the sum of score was $>5$. 
CCQ is a combination of the Rome II criteria (frequency), the Patient Assessment of Constipation-Symptoms (PAC-SYM: severity), and the use of laxative. The Cronbach's $\alpha$ coefficient for the six-item CCQ in Indonesian language was 0.739 ; thus, the questionnaire was considered to be reliable and valid.

Stool consistency was examined by using The Bristol Stool Scale (Blake, Raker \& Whelan, 2016). It was categorised into seven types of scale, i.e. type 1 (separate hard lumps, like nuts), type 2 (lumpy sausage-shaped), type 3 (sausage-shaped with cracks on the surface), type 4 (sausage or snakeshaped with a smooth and soft surface), type 5 (soft blobs with clear cut edges), type 6 (fluffy pieces with ragged edges, mushy stool) and type 7 (watery or no solid pieces). According to these categories, types 1-2 were classified as constipated stool type, types 3-4 were the ideal stool type, and types 5-7 happen when diarrhoea is present.

\section{Gastrointestinal symptoms}

The severity of gastrointestinal symptoms, like abdominal pain, bloating and flatulence were monitored before and after the intervention period by using a one-dimensional visual analogue scale (VAS). All subjects were required to rank each symptom based on a 0-10 scale, where 0 indicated no symptom, 1-3 were mild symptoms, 4-6 were moderate symptoms, and 7-10 indicated severe symptoms (Breivik et al., 2008).

\section{Dietary intake}

Subjects were provided with a food diary in the form of a 7-day "food catalogue' to record the amount of foods eaten during the day. A trained health practitioner and nutritionist taught the subjects on how to record their daily food consumption.

Table 1. Nutritional composition of Group A (6g, active control group) and Group B (12g, intervention group) PDX beverages ${ }^{\dagger}$

\begin{tabular}{|c|c|c|}
\hline & $\begin{array}{c}\text { Group } A^{\ddagger} \\
(6 g, \text { active control group })\end{array}$ & $\begin{array}{c}\text { Group } B^{\S} \\
(12 g, \text { intervention } \\
\text { group })\end{array}$ \\
\hline Trade name & Fibe Mini & Fibe Mini \\
\hline Form & Ready-to-drink & Ready-to-drink \\
\hline \multicolumn{3}{|l|}{ Composition } \\
\hline \multicolumn{3}{|c|}{ Serving size $100 \mathrm{ml}$ containing } \\
\hline Energy, kcal & 50 & 100 \\
\hline Protein, g & 0 & 0 \\
\hline Total fat, g & 0 & 0 \\
\hline Carbohydrate, g" & 10.9 & 21.8 \\
\hline PDX, $\mathrm{g}^{\dagger \dagger}$ & 6.0 & 12.0 \\
\hline Sugar, g & 9.0 & 18.0 \\
\hline Sodium, mg & 16.5 & 33.0 \\
\hline
\end{tabular}

†Ingredients: saccharides (sugar, high fructose corn syrup, oligosaccharide), polydextrose, carbon dioxide, acidulant, fragnance, tomato pigment and flavour enhancer (amino acids)

¥One serving consumed per day (10 AM)

$\S$ Two servings consumed per day (10 AM, 3PM)

"1g available carbohydrate provides energy: $4.1 \mathrm{kcal}$ (Kim \& Choi, 2015)

${ }^{\dagger \dagger}$ Equivalent to $1 \mathrm{kcal} / \mathrm{g}$, provided by the SCFA produced from its partial fermentation by the microbiota (Do Carmo et al., 2016) 
Detailed example on how to record the intake was given on the front page of the diary, including the time of consumption (breakfast, lunch, dinner and snack time), food type, and the amount of eaten item per unit.

\section{Test beverage product and compliance}

The test beverage product was a PDX (prebiotic) beverage (FibeMini $\left.{ }^{\circledR}\right)$ manufactured by Otsuka Pharmaceutical Co., Ltd, Tokyo, Japan. The nutritional composition of the test beverage product per $100 \mathrm{ml}$ is described in Table 1 . The test beverage product was analysed at an accredited laboratory by the Japanese Government, Japan Food Research Laboratories, Tokyo, Japan No. 19065330001-0101.

Subjects were followed-up via group messenger, which provided daily instruction and coordination, as well as a reminder for them to complete their food diary throughout the study. Subjects' compliance was measured with two mechanisms, i.e. a picture of the finished bottle was sent to the group messenger and empty bottles returned to the receptionist. The outcome investigator $(\mathrm{LH})$ further cross-checked that the number of pictures sent and returned bottles were equal in quantity to the ones distributed per person.

\section{Statistical analysis}

The sample size calculation followed the rule of thumb for a pilot study by Julious (2005) with a minimum sample size of 12 subjects per group. Data were analysed by IBM SPSS Statistics V21.0.0 (IBM Corporation, Armonk, NY, USA). The Kolmogorov-Smirnov test assessed the normality of data distribution. Results of the analysis were mainly reported using descriptive statistics with 95\% CI. Group A (6g PDX, active control group) was compared with Group B (12g PDX, intervention group) with respect to the primary outcome variables, like bowel habits and gastrointestinal symptoms. At baseline, Independent $t$-test and Chi-Square Test were performed to evaluate between-group analysis for continuous and categorical variables, respectively. Data about age, body mass index, dietary intake, constipation score, gastrointestinal symptoms score (e.g. abdominal pain, bloating and flatulence) were presented as mean \pm standard error of mean (SEM). Categorical variables about gender and work place were presented as proportions (n, \%). Furthermore, other categorical variables like compliance, stool frequency, stool consistency and gastrointestinal symptoms were analysed and compared between groups using Chi-Square Test. Changes in constipation score and gastrointestinal symptoms from baseline point within and between groups were compared using the General Linear Model repeated measure ANOVA analysis. Sub-analysis, by adjusting for baseline values and energy intake, was performed due to different starting points and between-group intake. Considered as a confounder, the values of these variables at baseline point and energy intake were therefore analysed as a covariate.

\section{RESULTS}

Table 2 describes the baseline characteristics of the subjects. Of the 24 subjects, 11 (45.8\%) were male and $13(54.2 \%)$ were female workers, respectively. The majority of subjects came from the Head Office (41.7\%), followed by Pasar Rebo branch (33.3\%) and Tangerang branch (25\%). Both Groups A and B were comparable in age, BMI, gender, work place, dietary intake and bowel habits. The subjects were sufficiently constipated, indicated by having a constipation score of $>5$, with $9.8 \pm 2.3$ and $8.1 \pm 1.7$ for Group $A$ and Group B, respectively. 
Table 2. Baseline characteristics of the subjects $(n=24)$

\begin{tabular}{|c|c|c|c|c|}
\hline \multirow{2}{*}{ Characteristics } & \multirow{2}{*}{$\begin{array}{c}\text { Overall } \\
(n=24)\end{array}$} & \multicolumn{2}{|c|}{ Polydextrose (PDX) } & \multirow{2}{*}{$p$-value } \\
\hline & & Group A $(n=12)$ & Group $B(n=12)$ & \\
\hline Age (year), Mean \pm SEM & $27.2 \pm 0.9$ & $27.1 \pm 1.4$ & $27.3 \pm 1.3$ & 0.89 \\
\hline Body mass index $\left(\mathrm{kg} / \mathrm{m}^{2}\right)$, Mean $\pm \mathrm{SEM}$ & $22.0 \pm 0.3$ & $22.1 \pm 0.6$ & $21.9 \pm 0.3$ & 0.65 \\
\hline Gender, $n(\%)$ & & & & $0.22^{\ddagger}$ \\
\hline Male & $11(45.8)$ & 7 (58.3) & $4(33.3)$ & \\
\hline Female & $13(54.2)$ & $5(41.7)$ & $8(66.7)$ & \\
\hline Work place, $n(\%)$ & & & & $0.59^{\ddagger}$ \\
\hline Pasar Rebo & $8(33.3)$ & $4(33.3)$ & $4(33.3)$ & \\
\hline Tangerang & $6(25.0)$ & $4(33.3)$ & $2(16.7)$ & \\
\hline Head Office (Jakarta) & $10(41.7)$ & $4(33.3)$ & $6(50.0)$ & \\
\hline \multicolumn{5}{|l|}{ Dietary intake } \\
\hline Energy (kcal), Mean \pm SEM & $1355 \pm 110$ & $1516 \pm 195$ & $1194 \pm 90$ & 0.15 \\
\hline Protein $(\mathrm{g})$, Mean \pm SEM & $72.0 \pm 8.3$ & $81.1 \pm 13.1$ & $62.9 \pm 9.9$ & 0.28 \\
\hline$\%$ of daily intake ${ }^{\S}$ & 21.8 & 21.9 & 21.3 & \\
\hline Carbohydrate (g), Mean \pm SEM & $152.6 \pm 13.7$ & $162.6 \pm 25.1$ & $142.7 \pm 11.6$ & 0.48 \\
\hline$\%$ of daily intake $\S$ & 46.2 & 44.0 & 49.0 & \\
\hline Total fat (g), Mean \pm SEM & $47.5 \pm 4.2$ & $55.1 \pm 6.4$ & $40.0 \pm 4.7$ & 0.07 \\
\hline$\%$ of daily intake $\S$ & 32.6 & 33.8 & 31.2 & \\
\hline Fibre (g), Mean \pm SEM & $7.5 \pm 0.8$ & $8.3 \pm 1.4$ & $6.6 \pm 0.9$ & 0.32 \\
\hline \multicolumn{5}{|l|}{ Bowel function } \\
\hline $\begin{array}{l}\text { Constipation mean score, } \\
\text { Mean } \pm \text { SEM }\end{array}$ & $8.9 \pm 0.4$ & $9.8 \pm 0.6$ & $8.1 \pm 0.5$ & 0.06 \\
\hline
\end{tabular}

Group A (6g, active control group); Group B (12g, intervention group)

tbetween group comparison by independent $t$-test $(p<0.05)$

‡between group comparison by chi-square test $(p<0.05)$

${ }^{\S}$ Rubner energy conversion factors: $4.1 \mathrm{kcal} / \mathrm{g}$ (protein), $4.1 \mathrm{kcal} / \mathrm{g}$ (carbohydrate), $9.3 \mathrm{kcal} / \mathrm{g}$ (fat) (Kim \& Choi, 2015)

Table 3 shows the changes in constipation score and gastrointestinal symptoms: abdominal pain, bloating and flatulence from baseline to endline. Based on the mixed linear model repeated measure analysis, it was observed that the overall consumption of PDX beverage was effective in reducing constipation mean score $[(\Delta M=-4.50 \pm 0.66 ; 95 \%$ CI (-5.87--3.13)]. Results from further analysis with adjustment for baseline values and energy intake demonstrated that subjects who consumed $12 \mathrm{~g}$ PDX had a $4.9 \%$ lower constipation mean score $(\Delta M=-4.96 \pm 0.96)$ compared to those who consumed $6 \mathrm{~g} \operatorname{PDX}(\Delta M=$ $-4.04 \pm 0.96)$.

At endline, both groups consuming either $6 \mathrm{~g}$ or 12 PDX did not show significant differences in the observed gastrointestinal symptoms, like abdominal pain $(\Delta M=-0.08 \pm 0.49)$, bloating $(\Delta M=-0.29 \pm 0.37)$ and flatulence $(\Delta M=-0.17 \pm 0.47)$. There was a higher tendency for subjects who consumed 12 PDX to have less abdominal pain $(M=0.25 \pm 0.64)$ compared to those who consumed 6g PDX, but it did not reach statistical significance. Based on 
Table 3. Result from pilot study comparing 7-day bowel habits and gastrointestinal symptoms scores $(n=24)$

\begin{tabular}{lcccc}
\hline Outcome measure & $\begin{array}{c}\text { Baseline point } \\
(n=24)\end{array}$ & $\begin{array}{c}\text { Endline } \\
(n=24)\end{array}$ & Mean differences $(95 \%$ CI) & $\begin{array}{c}\text { Group } x \\
\text { Trial }\end{array}$ \\
\hline Bowel habits & & & & \\
Constipation score & & & & \\
$\quad$ Overall & $8.92 \pm 0.42$ & $4.42 \pm 0.65^{*}$ & $-4.50 \pm 0.66(-5.87--3.13)$ & 0.52 \\
$\quad$ 6g PDX & $8.92 \pm 0.00^{\ddagger}$ & $4.88 \pm 0.96^{* \ddagger}$ & $-4.04 \pm 0.96(-6.03--2.04)$ & \\
12g PDX & $8.92 \pm 0.00^{\ddagger}$ & $3.95 \pm 0.96^{* \ddagger}$ & $-4.96 \pm 0.96(-6.96--2.97)$ & \\
Gastrointestinal symptoms & & & \\
Abdominal Pain & & & & \\
$\quad$ Overall & $0.83 \pm 0.30$ & $0.75 \pm 0.43$ & $-0.08 \pm 0.43(-1.09-0.923)$ & 0.29 \\
$\quad$ 6g PDX & $0.83 \pm 0.00^{\ddagger}$ & $1.25 \pm 0.64^{\ddagger}$ & $0.42 \pm 0.64(-0.90-1.75)$ & \\
$\quad$ 12g PDX & $0.83 \pm 0.00^{\ddagger}$ & $0.25 \pm 0.64^{\ddagger}$ & $-0.58 \pm 0.64(-1.91-0.75)$ & \\
Abdominal Bloating & & & & \\
$\quad$ Overall & $2.00 \pm 0.45$ & $1.71 \pm 0.39$ & $-0.29 \pm 0.37(-1.25-0.66)$ & 0.97 \\
$\quad$ 6g PDX & $2.00 \pm 0.00^{\ddagger}$ & $1.69 \pm 0.53^{\ddagger}$ & $-0.31 \pm 0.53(-1.41-0.83)$ & \\
$\quad$ 12g PDX & $2.00 \pm 0.00^{\ddagger}$ & $1.72 \pm 0.53^{\ddagger}$ & $-0.27 \pm 0.54(-1.39-0.83)$ & \\
Flatulence & & & & \\
$\quad$ Overall & $2.71 \pm 0.51$ & $2.54 \pm 0.52$ & $-0.17 \pm 0.47(-1.27-0.94)$ & 0.55 \\
$\quad$ 6g PDX & $2.71 \pm 0.00^{\ddagger}$ & $2.82 \pm 0.66^{\ddagger}$ & $0.17 \pm 0.66(-1.26-1.49)$ & \\
$\quad$ 12g PDX & $2.71 \pm 0.00^{\ddagger}$ & $2.26 \pm 0.66^{\ddagger}$ & $-0.44 \pm 0.66(-1.82-0.93)$ & \\
\hline
\end{tabular}

Data are displayed as mean $\pm \mathrm{SEM}$; CI, Confidence Interval

${ }^{*} p<0.05$, Bonferroni; the intervention effect as the difference in change-from baseline within the time points

${ }^{\dagger}$ Group $\mathrm{x}$ Trial interaction represents the treatment effect as the difference in change-from baseline between the two groups

‡adjusted for baseline point and energy intake

the analogue scale, both groups had mild abdominal bloating (6g PDX: $M=$ $1.69 \pm 0.53 ; 12 \mathrm{~g}$ PDX: $M=1.72 \pm 0.53)$ and mild flatulence (6g PDX: $M=2.82 \pm 0.66$; 12g PDX: $M=2.26 \pm 0.66)$; but again, these did not reach statistical differences.

Table 4 shows that the proportion of subjects consuming either $6 \mathrm{~g}$ or $12 \mathrm{~g}$ PDX did not differ significantly in terms of defecation frequency, stool consistency score, abdominal pain, bloating and flatulence. After a sevenday consumption of PDX beverage, $87.5 \%$ of the subjects had desirable defecation frequency. Of them, there was a trend whereby more subjects with a seven-day consumption of $12 \mathrm{~g}$ PDX $(91.7 \%)$ to experience "never $<3$ times defecation frequency per week". A similar trend was shown in stool consistency, where majority of the subjects had no difficulty passing stool or had normal stool consistency. In total, more than half of the constipated subjects (58.3\%) had type 4 stool consistency at the end of the study. In addition, in terms of compliance, Group A subjects consumed on average $100 \%(700 \mathrm{ml})$ and Group B consumed $100 \%(1400 \mathrm{ml})$ of the test beverage product. Therefore, subjects in both Group A and Group B were fully compliant (100\%).

Furthermore, all subjects $(n=24)$ reported several constipation-related symptoms, such as abdominal pain, bloating and flatulence at the beginning 


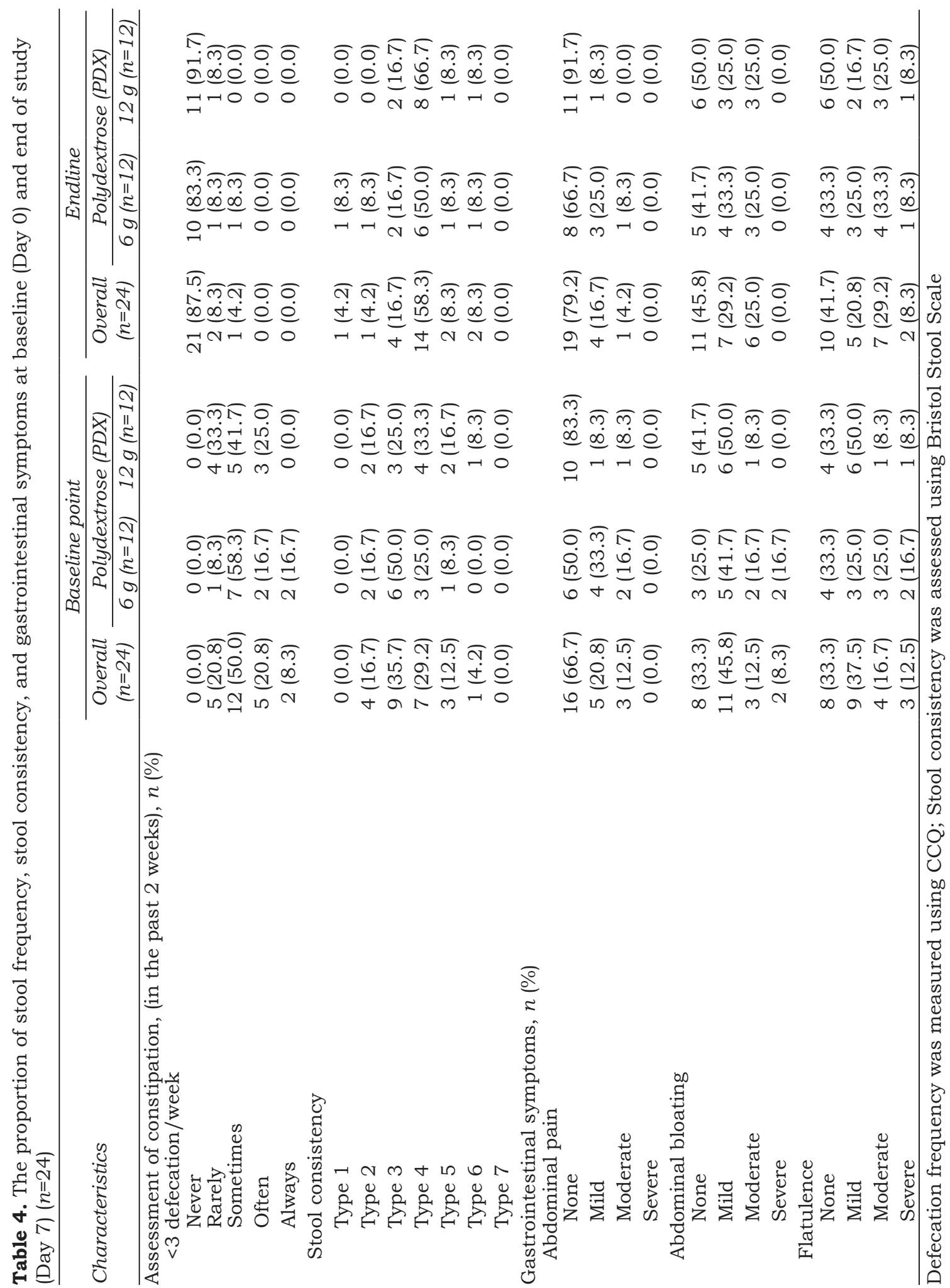


of the study. Of these symptoms, 23 were in Group A (6g PDX) and 17 were in Group B (12g PDX). Of the 40 reported symptoms, eight subjects reported abdominal pain [Group A: mild: 4 (33.3\%), moderate: 2(16.7\%); Group B: mild: 1 (8.3\%), moderate: 1 (8.3\%)]; 16 subjects were bloated (Group A: mild: 5 (41.7\%), moderate: 2 (16.7\%), severe: 2 (16.7\%); Group B: mild: 6 (50.0\%), moderate: 1 (8.3\%)]; and 16 subjects had flatulence [Group A: mild: 3 (25\%), moderate: 3 (25\%), severe: 2 (16.7\%); Group B: mild: 6 (50\%), moderate: 1 (8.3\%), severe: $1(8.3 \%)]$.

Based on the data reported in Table 4, out of the total 40 reported symptoms, 32 remained unresolved after the consumption of PDX beverage over seven days. However, it was clear that improvement in abdominal pain, bloating and flatulence was seen by the end of the study for those who consumed PDX beverage.

\section{DISCUSSION}

Nowadays, the mainstream Indonesian young adults are consuming more protein than their body requires, carbohydraterich foods, and less dietary fibre (Table 2). With respect to dietary fibre, it has been well-documented that higher fibre intake reduces the risk of all-cause cardiovascular mortality, the incidence of non-communicable diseases, and constipation (Mayor, 2019; Yang et al., 2012). Considering the low intake of dietary fibre, it is then reasonable to suggest whether supplementation of dietary fibre through products will improve bowel habits. Therefore, this study was designed to investigate whether PDX in the form of ready-todrink beverage demonstrates a beneficial effect on bowel habits.

Identifying the fact that the constipation-alleviating effect of PDX in humans has been widely documented in different dose-responses in clinical trials (Do Carmo et al., 2016), the present study had at least three distinctive characteristics. Firstly, the present study was performed in Indonesian young adults with a constipation problem. This strongly suggested that the studied population was sufficiently constipated, which is likely to build on the strength of evidence regarding the constipation-alleviating effect of PDX beverage consumption. Secondly, the average fibre intake of subjects was $7.5 \pm 4.1 \mathrm{~g} /$ day, which implied that only one-third of the daily fibre intake recommendation by WHO (2003) - 25g/ day was fulfilled by the subjects. This finding was in line with the previous data observed by the Ministry of Health (MOH) Indonesia (2008), where Indonesians have a low level of dietary fibre intake of around $10.5 \mathrm{~g} /$ day. Thirdly, a readyto-drink beverage containing PDX was used, while in most clinical trials, PDX was incorporated in powder or yoghurt (Ibarra et al., 2019; Magro et al., 2014).

PDX is one of the non-digestible food ingredients studied for its prebiotic potential. Its prebiotic potential has been demonstrated in altering the gut microbiota, which results in relieving or preventing constipation (Ibarra et al., 2019). Besides being an outstanding functional fibre, it has been accepted as a dietary fibre in more than 20 countries and approved in over 60 countries to be incorporated into foods to boost fibre content, as well as to replace sugar and fat (Flood, Auerbach \& Craig 2004). It is reported that a daily PDX consumption of up to $90 \mathrm{~g}$ or $50 \mathrm{~g}$ in a single dose is well tolerated by humans. Besides, it has been established that a regular intake of 4-12g PDX improves physiologic functions without adverse effects (Jie et al., 2000). While the majority of available data on the constipation-alleviating effect of PDX has been investigated in healthy subjects (Ibarra et al., 2019), data on 
subjects experiencing constipation are lacking. The current study is the first to demonstrate the effects of consuming PDX (prebiotic) beverage, containing 6g and $12 \mathrm{~g}$ PDX once a day for seven days in constipated subjects. The observed efficacy was shown to be comparable to what has been found with PDX doseresponses in other clinical trials (Ibarra et al., 2019; Duncan et al., 2018).

In the current study, the constipation-alleviating effect of PDX beverage consumption was observed at the end of the study (Day 7), that was, for consuming either one serving of PDX beverage containing $6 \mathrm{~g} /$ day PDX or two servings of the same product, containing $12 \mathrm{~g} /$ day PDX. Subjects who consumed $12 \mathrm{~g}$ PDX once a day experienced a greater reduction in overall constipation mean score compared to those who consumed 6g PDX once a day. Additionally, there was a higher number of subjects who reported constipation relief, with $91.7 \%$ of subjects having desirable defecation frequency ( $>3$ defecation per week), and $66.7 \%$ who had ideal stool consistency (type 4) after seven days of PDX beverage consumption.

Recent trials demonstrated a clear dose-response effect for PDX (Ibarra et al., 2019; Shimada et al., 2015), although the reported constipation-alleviating effects in these studies were shown after a period of 14 days. Also, data on $6 \mathrm{~g}$ dosage are rarely investigated. Based on this present study findings, consuming one serving size of PDX beverage (100ml) containing $6 \mathrm{~g}$ PDX for seven days was able to relieve and prevent constipation. This suggests that incorporating PDX into ready-to-drink beverage has shed new light on the intervention for constipated subjects. This accounts for its practical and safe one-time consumption with a better laxative effect in real-life setting (per unit bottle). PDX was also shown to be efficient in this form of product, indicating that PDX consumption in liquid form appears to have a larger constipation-alleviating effect over a shorter period of time compared to interventions designed using solid form (e.g. yoghurt or powder) with a longer period of time. However, further trials need to be conducted to confirm the efficacy of PDX in different product formats. Also, subjects who consumed one serving size of PDX beverage could achieve an additional 20\% in fibre intake (BPOM, 2016), thus, this may help to increase the overall daily fibre intake of the Indonesian society.

Do Carmo et al. (2016) described that the possible mechanism of action of PDX in improving the ease of bowel movement is its ability in stimulating the human colon by reducing bowel transit time, increasing total weekly bowel frequency without inducing adverse gastrointestinal symptoms and by producing soft stools. Shimada et al. (2015) found out that PDX consumption for seven days effectively changed bowel function (stool frequency increased from 3 times to 7 times per week) and reported desirable stool consistency like a sausage or snake-shaped with a smooth and soft surface over an eightweek consumption period. Similarly, Ibarra et al. (2019) investigated the bowel habits of an adult population ( $n=192$, mean age $42.7 \pm 18.8$ ) in a double-blind, randomised, placebo-controlled trial, where subjects were assigned into four groups of intervention: i.e. $12 \mathrm{~g}$ PDX or $8 \mathrm{~g}$ PDX and $4 \mathrm{~g}$ maltodextrin or $4 \mathrm{~g}$ PDX and $8 \mathrm{~g}$ maltodextrin or placebo $(12 \mathrm{~g}$ maltodextrin), for a period of 14 days. The efficacy of PDX consumption was observed on constipation score, with $12 \mathrm{~g}$ PDX daily consumption decreasing more constipation mean score than $8 \mathrm{~g}$ PDX or $4 \mathrm{~g}$ PDX. Thus, the regular consumption of $12 \mathrm{~g}$ PDX effectively increased the proportion of adults who were relieved from constipation from $54.0 \%$ to $79.0 \%$, with an increase in stool frequency 
by $>2$ defecations per week. But, the dose-response effect of PDX on stool consistency did not reach statistical significance due to the low incidence of constipation in the study population.

On the other hand, the mechanism of action of PDX (prebiotics) in exacerbating gastrointestinal symptoms remains debatable. Staudacher et al. (2014) described that the nature of PDX has various mechanisms, i.e. colonic-gas production by microbiota fermentation and altered intestinal motility. According to Do Carmo et al. (2016), PDX (prebiotics) remains undigested throughout the large intestine due to the long fermentation cycle, which stays usable as a carbon supply for the microbiota; therefore, it may stimulate either the growth or the activity of the microbiota. Then, the continuous fermentation of the colonic microbes results in a steady output of short-chain fatty acids (SCFA) and a little volume of gas (Röytiö \& Ouwehand, 2014; Hernot et al., 2009). Clinically, disrupted gas transport and inadequate gas evacuation may contribute to the development of abdominal distention, resulting in pain or flatulence out of proportion to the volume of gas trapped in a particular segment of the intestine. One suggested explanation is that PDX also stimulates the growth of methanogens, which then decreases the production of methane, increases the ileal and colon transit time, and reduces the amplitude of contraction, thus accelerating peristalsis and resulting in better intestinal motility (Waqar \& Rehan 2019). Consequently, this physiological mechanism may facilitate the positive results correlated with PDX intake in the improvement of bowel function, e.g. alleviating constipation and producing smoother stools in humans (Röytiö \& Ouwehand, 2014).

These current study findings are partly consistent with previous studies
(Ibarra et al., 2019; Duncan et al., 2018; Shimada et al., 2015), indicating that PDX consumption helps to solve gastrointestinal symptoms. However, Duncan et al. (2018) observed that both regular $8 \mathrm{~g}$ and $12 \mathrm{~g}$ of PDX consumption over two weeks in chronically constipated adults did not improve subjectivereported symptoms, as compared to baseline. Adverse effects, such as abdominal pain (8g/day PDX: $27.5 \%$, 12g/day PDX: $20.0 \%$ ) and flatulence (8g/day PDX: $2.5 \%, 12 \mathrm{~g} /$ day PDX: $0.0 \%$ ) were not fully treated by the end of the study. In contrast to the earlier mentioned study, no abdominal cramps or other discomforts were reported by those who consumed PDX for four weeks (Shimada et al., 2015). In a recent study using different daily dose-response of PDX, Ibarra et al. (2019) discovered that consuming $12 \mathrm{~g} /$ day of PDX for 14 days resolved all reported adverse effects (e.g. abdominal discomfort, flatulence, abdominal pain upper, nausea) by the end of the study.

This study was feasibly successful due to the use of the CCQ diagnostic criteria developed by Chan et al. (2005) for determining constipation as an inclusion criteria. Considering the time frame of the current pilot study, CCQ was an ideal screening method for quick classification of constipation based on frequency, symptom severity and laxative use. Also, the questionnaire was chosen because it was considered easy to understand and has been proven to have a consistent and reproducible result. However, the use of the Likert Scale in the questionnaire administration may have led to bias, due to the unclear definition of each scale category, e.g. "sometimes", "often". This may have allowed subjects to give vague answers based on a general view of their current condition (high subjectivity). Furthermore, the compliance in consuming the PDX 
beverage was good; $100 \%$ of the provided test beverage products were consumed in both groups.

On the other hand, a drawback is worth mentioning. Although the present study hypotheses were supported statistically, this study was an early phase of a clinical trial with a focus on investigating whether PDX beverage affects bowel habits and relieve constipation. These findings are important as the basis evidence for larger research trials in future. Therefore, further research studies, including the use of placebo (control) group, longer intervention period (i.e. 28 days or longer), with a focus on more constipation-related symptoms or adverse effects, might be able to strengthen the positive effect of PDX (prebiotic) beverage consumption.

\section{CONCLUSION}

The subjects' bowel habits indicated by the overall constipation mean score was significantly lower in those who consumed two serving sizes of PDX beverage once a day $(200 \mathrm{ml})$, containing $12 \mathrm{~g}$ PDX (Group B, intervention group) than those who consumed one serving of the same product, containing $6 g$ PDX (Group A, active control group). Group B also had a higher percentage of desirable stool frequency and ideal stool consistency with fewer subject-reported gastrointestinal symptoms, compared to Group A.

In conclusion, this preliminary investigation has confirmed the potential of PDX (prebiotic) beverage consumption in constipation management. PDX has an important role in alleviating constipation, thus, consumption of PDX beverages can be recommended to constipated young adults with their existing dietary habits.

\section{Acknowledgment}

Sincere appreciation to all study partners of PT. Amerta Indah Otsuka, PT. Otsuka Distribution Indonesia and other parties involved for the support. Subjects and outcome investigator are gratefully acknowledged. Special thanks to Fithraturrahmah and Prof. Widjaja Lukito for help in reviewing the manuscript.

\section{Authors' contributions}

MYK, analysed and interpreted the data, reviewed and finalised the manuscript; NI, principal investigator, designed the study, wrote the manuscript; LH, outcome investigator (data collection), reviewed manuscript; CR, assisted in statistical analysis, compiled the data; FS, contributed in study design and reviewed the manuscript.

\section{Conflict of interest}

All authors have no conflict of interest regarding the publication of this manuscript. NI, LH, CR, and FS were the former scientific team of PT. Amerta Indah Otsuka at the time of study execution. MYK is the new scientific supervisor employed by PT. Amerta Indah Otsuka. This pilot study was supported by Otsuka Pharmaceuticals, Co., Ltd., the parent company of PT. Amerta Indah Otsuka, which provided the study product (Fibe-Mini). All authors disclose that the sponsor company had no influence in the execution of the study, including no input into the study design, data collection, analyses, or interpretation of the data, in the writing of the manuscript, and in the decision to publish the results.

\section{References}

Blake M, Raker J \& Whelan K (2016). Validity and reliability of the Bristol Stool Form Scale in healthy adults and patients with diarrhoeapredominant irritable bowel syndrome. Aliment Pharmacol Ther 44(7):693-703.

BPOM RI (2016). Peraturan Kepala Badan Pengawas Obat dan Makanan Republik Indonesia Nomor 9 Tahun 2016 tentang Acuan Label Gizi. Jakarta.

Breivik H, Borchgrevink P, Allen S, Rosseland L, Romundstad L, Breivik Hals E, Kvarstein G \& Stubhaug A (2008). Assessment of pain. $\mathrm{Br} J$ Anaesth 101(1):17-24.

Chan AO, Lam KF, Hui WM, Hu WH, Li J, Lai KC, Chan CK, Yuen MF \& Wong BC (2005). Validated questionnaire on diagnosis and symptom severity for functional constipation in the Chinese population. Aliment Pharmacol Ther 22(5):483-8. 
Chey WD (2017). Symposium report: an evidencebased approach to Ibs and Cic: applying new advances to daily practice: a review of an adjunct clinical symposium of the American College of Gastroenterology Meeting October 16, 2016 - Las Vegas, Nevada. Gastroenterol Hepatol 13(2 Suppl 1):1.

Costabile A, Fava F, Röytiö H, Forssten SD, Olli K, Klievink J, Rowland IR, Ouwehand AC, Rastall RA \& Gibson GR (2012). Impact of polydextrose on the faecal microbiota: a double-blind, crossover, placebo-controlled feeding study in healthy human subjects. Brit $J$ Nutr 108(3):471-81.

Do Carmo MMR, Walker JCL, Novello D, Caselato VM, Sgarbieri VC, Ouwehand AC, Andreollo NA, Hiane PA \& Dos Santos EF (2016). Polydextrose: physiological function, and effects on health. Nutrients 8(9):553.

Duncan PI, Enters-Weijnen CF, Emami N, McLean $\mathrm{P}$, Nunes T, Beaumont M, Crabbe R, Whelan K, Mark Scott S \& DeWit NJ (2018). Shortterm daily intake of polydextrose fiber does not shorten intestinal transit time in constipated adults: a randomized controlled trial. Nutrients 10(7):920.

Flood M, Auerbach M \& Craig S (2004). A review of the clinical toleration studies of polydextrose in food. Food Chem Toxicol 42(9):1531-42.

Forootan M, Bagheri N \& Darvishi M (2018). Chronic constipation: A review of literature. Medicine 97(20).

Hernot DC, Boileau TW, Bauer LL, Middelbos IS, Murphy MR, Swanson KS \& Fahey Jr GC (2009). In vitro fermentation profiles, gas production rates, and microbiota modulation as affected by certain fructans, galactooligosaccharides, and polydextrose. J Agric Food Chem 57(4):135461.

Ibarra A, Pelipyagina T, Rueffer M, Evans M \& Ouwehand AC (2019). Efficacy of polydextrose supplementation on colonic transit time, bowel movements, and gastrointestinal symptoms in adults: a double-blind, randomized, placebocontrolled trial. Nutrients 11(2):439.

Jie Z, Bang-yao L, Ming-Jie X, Hai-wei L, Zu-kang $Z$, Ting-song W \& Craig SA (2000). Studies on the effects of polydextrose intake on physiologic functions in Chinese people. Am J Clin Nutr 72(6):1503-1509.

Julious SA (2005). Sample size of 12 per group rule of thumb for a pilot study. Pharmaceut Statist 4(4):287-91.
Kim E, \& Choi J (2015). The evaluation of metabolizable energy in traditional Korean food for protein sources. J Ethnic Foods 2(4):179185.

Lee HJ, Choi JK, Ryu HS, Choi CH, Kang EH, Park KS, Min YW \& Hong, KS (2017). Therapeutic modulation of gut microbiota in functional bowel disorders. J Neurogastroenterol Motil 23(1):9.

Magro DO, de Oliveira LMR, Bernasconi I, de Souza Ruela M, Credidio L, Barcelos IK, Leal RF, de Lourdes Stesuko Ayrizono M, Fagundes JJ, de B Teixeira L, Ouwehand AC \& Coy CSR (2014). Effect of yogurt containing polydextrose, Lactobacillus acidophilus NCFM and Bifidobacterium lactis HNO19: a randomized, double-blind, controlled study in chronic constipation. Nutr J 13(1):1-5.

Mayor S (2019). Eating more fibre linked to reduced risk of non-communicable diseases and death, review finds. BMJ 364:1159.

MOH Indonesia (2008). Overweight due to lack of fibre. Ministry of Health, Indonesia.

Mounsey A, Raleigh MF \& Wilson A (2015). Management of constipation in older adults. Am Fam Physician 92(6):500-4.

Mugie SM, Benninga MA \& Di Lorenzo C (2011). Epidemiology of constipation in children and adults: a systematic review. Best Pract Res Clin Gastroenterol 25(1):3-18.

Philichi L (2018). Management of childhood functional constipation. J Pediatr Health Care 32(1):103-11.

Röytiö H \& Ouwehand A (2014). The fermentation of polydextrose in the large intestine and its beneficial effects. Benef Microbes 5(3):305-13.

Shimada M, Nagano N, Goto S, Ito K, Tsutsui T, Ando T, KAMIOkA H \& Ogawa T (2015). Effect of polydextrose intake on constipation in japanese dialysis patients: A triple-blind, randomized, controlled trial. J Nutr Sci Vitaminol 61(4):34553.

Staudacher HM, Irving PM, Lomer MC \& Whelan K. (2014). Mechanisms and efficacy of dietary FODMAP restriction in IBS. Nature Reviews Gastroenterology \& Hepatology 11(4): 256.

Vagias WM (2006). Likert-type scale response anchors. Clemson International Institute for Tourism \& Research Development, Department of Parks, Recreation and Tourism Management Clemson University. 
Wahab PA, Kadir AA, Lee YY, Ali SH \& Yusoff DM (2019). Chronic constipation among community-dwelling older people in the East Coast region of Peninsular Malaysia. Makara Journal of Health Research 23(3):8.

Waqar SHB \& Rehan A (2019). Methane and constipation-predominant irritable bowel syndrome: entwining pillars of emerging neurogastroenterology. Cureus 11(5).

WHO (2003). Diet, Nutrition and the Prevention of Chronic Diseases. World Health Organization, Geneva. From https://www.who.int/ dietphysicalactivity/publications/trs916/en/ [Retrieved July 30 2020].
WHO (2020). Mean body mass index (BMI): situation and trends. World Health Organization, Geneva. From https://www.who.int/gho/ncd/ risk_factors/bmi_text/en/ [Retrieved July 30 2020].

Yang J, Wang HP, Zhou L \& Xu CF (2012). Effect of dietary fiber on constipation: a meta-analysis. World J Gastroenterol 18(48):7378.

Yudiyanto AR (2018). Obesity and functional constipation in children. Paediatr Indones 58(1): 1 . 